\title{
Partial Nasopharyngeal Stenosis: Presentation of an Unusual Case
}

\author{
Chaand Bibi*, Maham Rehman, Ahmad Hasan Khan, Abdal Niaz and Ihsan Ullah \\ Rehman Medical Institute, Pakistan
}

Submission: September 27, 2021; Published: November 10, 2021

*Corresponding author: Chaand Bibi, Rehman Medical Institute, Peshawar, Pakistan

\begin{abstract}
We herein report a rare case of a forty-one-year-old male that reported to Rehman Medical institute, Peshawar, Pakistan on 20th March 2021 with partial nasopharyngeal stenosis after undergoing Functional Endoscopic Sinus Surgery complex and Uvelopalatopharyngoplasty two months ago. As a result of this procedure, he developed scar tissue due to which there was a regurgitation of fluids from his nostrils and difficulty breathing. He underwent surgical intervention where dense, thick, fibrotic tissues were extracted, edges were freshened, and a large passage was created between the oropharynx and the nasopharynx.
\end{abstract}

Keywords: Nasopharyngeal surgery; Constriction; Sleep apnea

\section{Introduction}

Nasopharyngeal stenosis is an uncommon occurrence that ensues as a result of pathological etiology where there is a narrowing of various degrees within the nasopharynx between the choana and the oropharynx [1]. This complication occurs due to the formation of scar tissue that may manifest in a variety of ways including circumferential narrowing, a web, or bands [1]. This is secondary to a disease or traumatic insult caused by procedures such as Uvelopalatopharyngoplasty, tonsillectomy, adenoidectomy, and pharyngeal reconstruction for velopharyngeal insufficiency [2]. Previously, it was noted that NPS occurred mostly due to tertiary syphilis of the mouth, pharynx, and palate as these were treated with caustic chemicals. Despite the extensive range of therapeutic options available, including surgical excision, there is a high chance of recurrence. In this report, the clinical findings and management of a patient with partial NPS are outlined.

\section{Case Report}

A forty-one-year-old man with no prior co-morbidities presented to the ENT out-patient department with complaints of regurgitation of liquids from the nose after taking fluids, nasal obstruction associated with sore throat and anosmia for the past 2 months. His symptoms started after he underwent Functional endoscopic sinus surgery and Uvelopalatopharyngoplasty in December 2020 due to sleep apnea and snoring. He had been taking oral antibiotics and steroids for the same duration, but his symptoms persisted. On physical examination, his vitals were within the optimal range. The uvula along with the tonsils was absent, there was decreased airflow through the nostrils, and there were no structural anomalies in his teeth. There was the adherence of posterior tonsillar pillars to the oropharyngeal posterior wall. In addition, there was a pinhole appearance between the oropharynx and the nasopharynx (Figure 1). Therefore, prerequisite investigations for the procedure were done which showed normal complete blood count and nonreactive virology.

The patient underwent surgery for nasopharyngeal stenosis under general anesthesia with endotracheal intubation. The perioperative findings were consistent with preoperative findings and the posterior tonsillar pillars adhered to the oropharyngeal posterior wall by a thick fibrotic tissue. The tissue was dense, fibrotic, and avascular. A slit incision of $3 \mathrm{~cm}$ was made vertically at the posterior wall by electrocoagulation. The posterior tonsillar pillars were released from the posterior oropharyngeal wall. The opening was widened laterally on both sides and edges were trimmed as well as freshened by cauterization. A passage was created between the oropharynx and nasopharynx to avoid regurgitation. The post-op period was uneventful therefore he was discharged on the first post-op day. After four weeks follow up, he was reassessed and no recurrence of stenosis and accompanying symptoms was noted (Figure 2). 


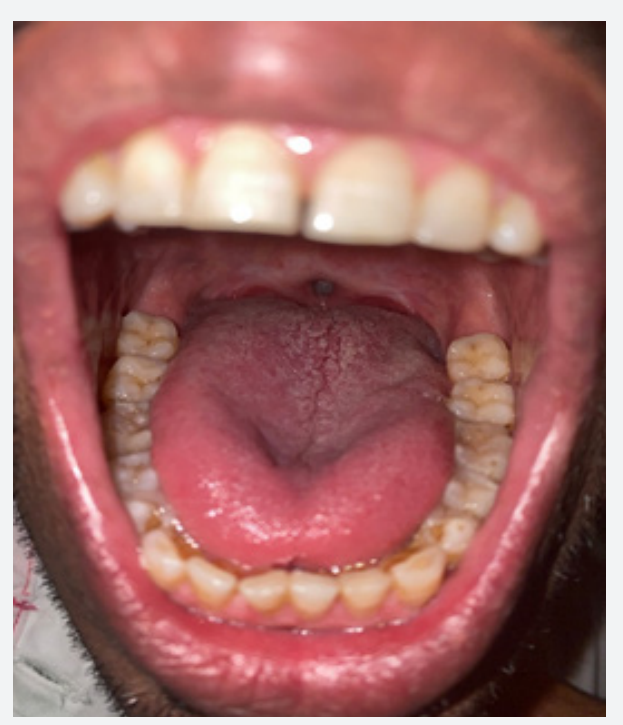

Figure 1: On physical examination of the patient, there was a pinhole appearance between the oropharynx and nasopharynx.

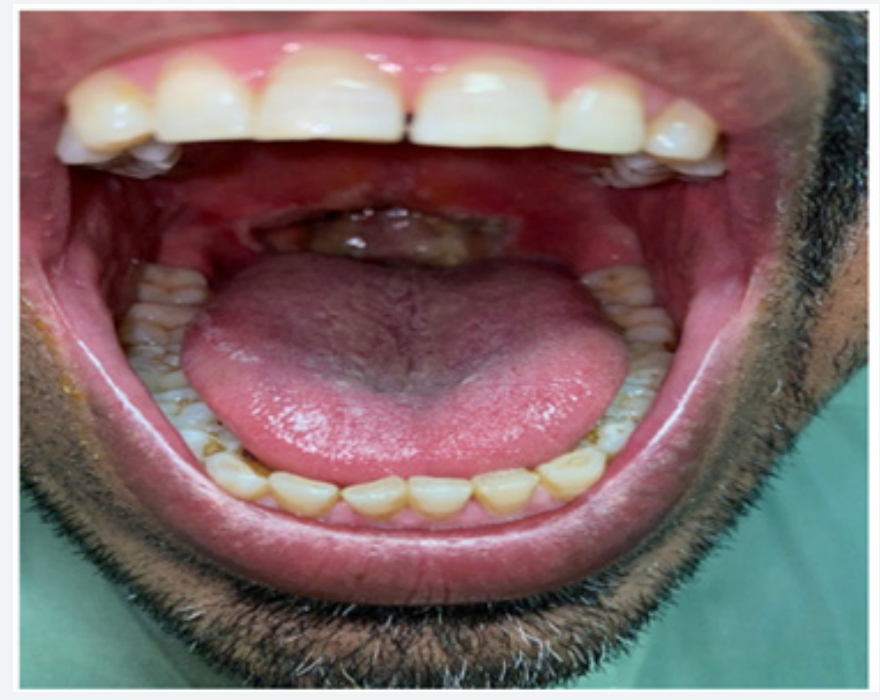

Figure 2: Immediate post-op picture showing patency created between the oropharynx and nasopharynx.

\section{Discussion}

Nasopharyngeal stenosis is a rare complication with its true incidence being hard to determine. It can be classified according to its etiology, with primary NPS occurring due to a disease process such as those seen in the past as a complication of tertiary syphilis of the mouth, tuberculosis, and other infectious diseases[3]. While secondary NPS is iatrogenic with it most commonly resulting from pharyngeal surgeries for obstructive sleep apnea and radiation therapy for nasopharyngeal carcinoma. Cases of undetermined etiology have also been reported, as that seen in a case report in Turkey [3]. The symptoms that patients display can vary according to the degree of stenosis. Most common complaints include persistence of obstructive sleep apnea, snoring, dysphagia, otalgia, and anosmia. No previous incidence of regurgitation of fluids from the nose, as seen in our patient, has been seen in the literature.

Preoperative diagnosis and extent of stenosis are best determined by rigid nasal endoscopic examination and flexible nasopharyngolaryngoscopy. Treatment options vary; however, the only curative option present is surgery. Many surgical techniques exist including the creation of various pharyngeal flaps. A study in Cairo University, department of Medicine described promising results in 2016 by the use of palatal eversion with follow-up results showing a freely mobile soft palate with no nasopharyngeal stenosis on 10 patients [4]. Another study in Egypt that employed 
a modified Z-palatoplasty correction concluded similar results including that the procedure was effective, economical, and easily applicable [5]. A modified surgical palatoplasty technique was reported on 8 patients by a preliminary retrospective study in 2020. In this, a varied technique to bivalved palatal transposition flaps was used. This study also described promising results with none of the patients showing follow-up complications [6]. A study in Kenya documented the successful treatment of NPS using a facial artery Musculo mucosal flap as an alternative [7]. Less invasive techniques such as that using $\mathrm{CO}_{2}$ laser excision and balloon dilation [8], and application of mitomycin $\mathrm{C}$ have also shown favorable results [9].

In summary, NPS is a rare and difficult case to treat successfully. With the advent of many techniques and with no standard technique available, a detailed assessment of the patient is needed to ensure that the best approach for the patient is chosen. While careful operative technique and postoperative management in primary surgery are essential to prevent further cases.

\section{References}

1. Manekekar G (2018) Nasopharyngeal stenosis. Medscape J Med.

2. Smith ME (2005) Prevention and treatment of nasopharyngeal stenosis. Operative Techniques in Otolaryngology-Head and Neck Surgery 16(4): 242-247.

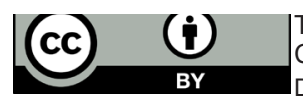

This work is licensed under Creative Commons Attribution 4.0 Licens DOI: 10.19080/JETR.2021.06.555688
3. Korkmaz H, Selcuk OT, Tatar EC, Saylam G, Ozdek A (2012) Complete Nasopharyngeal Stenosis: Presentation of a Rare Case. Eurasian J Med 44(3):185-187.

4. Abdel-Fattah G (2016) Palatal eversion for the treatment of combined nasopharyngeal stenosis and tonsillar pillars adhesion. Int J Pediatr Otorhinolaryngol 90: 227-230.

5. Eesa M, Hendawy E, El-Anwar MW (2021) Modified Z-Palatoplasty for Correction of Acquired Nasopharyngeal Stenosis Following Palatal Surgery: A Case Series. Cleft Palate Craniofac J 10556656211021702.

6. Cammaroto G, Stringa LM , Cerritelli L, Bianchi G, Meccariello G, et al. Acquired Nasopharyngeal Stenosis Correction Using a Modified Palatal Flaps Technique in Obstructive Sleep Apnea (OSA) Patients. Int J Environ Res Public Health 17(6): 2048.

7. Nangole FW, Khainga SO. FAMM Flap in Reconstructing Postsurgical Nasopharyngeal Airway Stenosis. Plast Surg Int 276058.

8. Sidell D, Chhetri DK (2011) $\mathrm{CO}_{2}$ laser ablation and balloon dilation for acquired nasopharyngeal stenosis: a novel technique. Laryngoscope 121(7): 1486-1489.

9. Nitassi S, Kissi M, Rkain I, Benbouzid A, Oujilal A, et al. (2019) Nasopharyngeal Stenosis: A Rare Radiotherapy Complication. Indian J Otolaryngol Head Neck Surg 71(Suppl 1): 29-31.

Your next submission with Juniper Publishers
will reach you the below assets
- Quality Editorial service
- Swift Peer Review
- Reprints availability
- E-prints Service
- Manuscript Podcast for convenient understanding
- Global attainment for your research
- Manuscript accessibility in different formats
( Pdf, E-pub, Full Text, Audio)
- Unceasing customer service
Track the below URL for one-step submission
https://juniperpublishers.com/online-submission.php

